\title{
Autoshaping with nine consecutive conditioned stimuli in the pigeon
}

\author{
RICHARD PISACRETA, DAVID E. GOUGH, CATHY POTTER, and RICHARD CROSS \\ Ferris State College, Big Rapids, Michigan
}

\begin{abstract}
Four naive pigeons were trained with an autoshaping procedure that provided nine consecutive conditioned stimuli (CS1-CS9). The 18-sec CS presentation period was divided into nine 2-sec intervals. During each 2-sec interval, a different response key was lighted with white light. Hence, the birds were provided with nine sequential CS stimuli. After the ninth CS, 4-sec access to grain was provided, followed by a 30 -sec intertrial interval. Three of the four birds pecked the fourth key to light (CS4) within 1-23 trials. The fourth bird pecked CS8 first, during the 34th trial. When the order in which the keys lighted was rearranged, each bird continued to peck one of the first three keys to light.
\end{abstract}

Experimentally naive pigeons are frequently trained to peck response keys by the autoshaping procedure introduced by Brown and Jenkins (1968). A naive pigeon is taught to eat from a grain feeder. A trial consists of an 8-sec presentation of a lighted response key (CS) followed by 4-sec access to grain (US) and a short intertrial interval. The pigeon is not required to peck the key in order to produce grain. A keypeck terminates the CS and produces the grain. Pigeons typically peck the lighted key after a few trials (CS-US pairings). Brown and Jenkins reported that their birds pecked the key after an average of 45 trials (range $=6-119$ ).

Another procedure employed by Brown and Jenkins (1968) involved presenting two consecutive CS stimuli on the same response key. A trial presented a white key light (CS1) for $8 \mathrm{sec}$, followed by a red key light (CS2) for $8 \mathrm{sec}$ and then the reinforcer. The mean number of trials that occurred before the keypeck emerged was 33 (range $=14-66$ ). Thus, the keypeck emerged sooner when two CS stimuli were provided than when only one CS was provided. Furthermore, although the white light (CS1) was more similar than the red light (CS2) to the white light that illuminated the grain during US deliveries, the first keypecks were emitted during the red keylight periods (CS2). Presumably, the closer a CS is temporally paired with a US, the stronger is the association of the two stimuli (Pavlov, 1927). Hence, the red light would be expected to occasion the first keypecks. An alternate view is that the informativeness of the CS, and not simply pairing of CS and US, is contributory to the emergence of autoshaped responses (e.g., Allaway, 1971; Egger \& Miller, 1963; Gamzu \& Williams, 1973). For example, Allaway presented a 2-sec tone CS followed by 6-sec presentation of tone plus key light CS. Some birds pecked the key infrequently, whereas others did not keypeck at all. The redundancy of the tone and keylight is offered to explain the results. Pecks to a key, however, reduce the time between

Reprints may be obtained from Richard Pisacreta, Department of Psychology, Ferris State College, Big Rapids, MI 49307. grain presentations (by canceling the rest of the CS interval) and are reinforced by the grain they produce. We felt that presenting several visual CS stimuli, spatially separated on response keys, should produce the first keypeck to the last CS presented if the pairing of CS and US is critical or produce a keypeck to the first CS if the informativeness of the CS is the controlling factor. In the present context, informativeness strictly refers only to the ability of the CS to predict the occurrence of the impending US.

\section{METHOD}

\section{Subjects}

Four experimentally naive 3 -year-old white Carneaux pigeons, maintained at $80 \% \pm 15 \mathrm{~g}$ of their free-feeding weights, were used.

\section{Apparatus}

The apparatus was a $35 \times 35 \times 37 \mathrm{~cm}$ operant chamber enclosed in a sound-attenuating hull. Figure 1 shows the response panel. The response panel, $37 \times 35 \mathrm{~cm}$, had $112.7-\mathrm{cm}$ (BRS/LVE Model 12116) response keys. Stimuli were rear-projected onto the keys by means of IEE in-line projectors (Model 1813-1820). The operating force of each key was approximately $0.16 \mathrm{~N}$. The horizontal and vertical distances

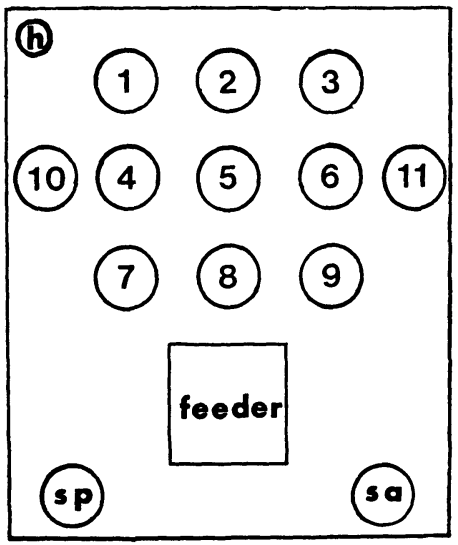

Figure 1. The response panel: The pecking keys are numbered 1 through 11. H, SP, and SA represent the houselight, speaker, and sonalert, respectively. 
between the keys were 8.1 and $6.4 \mathrm{~cm}$, respectively, center to center. A $6 \times 6 \mathrm{~cm}$ feeder aperture was centered on the wall $10 \mathrm{~cm}$ above the floor.

The feeder (BR/LVE Model 114-10) provided 4-sec access to grain. The houselight (" $h$ " in Figure 1), a GE 1820 lamp, provided light throughout each daily experimental session. Response Keys 10 and 11 were never illuminated. A ventilation fan and white noise delivered through the speaker masked extraneous noises. An E \& L Instruments MMD-1 computer and additional hardware recorded data and controlled experimental events.

\section{Procedure}

Each pigeon was trained to eat from the grain feeder within $2 \mathrm{sec}$ of the feeder's activation. The autoshaping procedure was then introduced. A trial presented nine CS stimuli followed by 4-sec access to grain. At trial onset, Key 1 presented white light for $2 \mathrm{sec}$. Key 1 was then darkened, and Key 4 was illuminated with white light for $2 \mathrm{sec}$. Every $2 \mathrm{sec}$, a different response key was lighted. The keys were lighted in the sequence $1,4,7,8,5,2,3,6$, and 9 (CS1-CS9). The key lights moved in vertical columns, from left to right, across the response panel. After Key 9 was lighted for $2 \mathrm{sec}$, it was darkened and the grain was presented. Thus, the 18-sec CS period was divided into nine 2-sec intervals, each accompanied by a different lighted key. A keypeck was never required. A 30-sec intertrial interval (ITI) followed grain delivery. The keys remained dark during the ITI. Sessions terminated after 50 trials.

After five sessions, the CS presentation order was changed. For the last two sessions of the study, the keys lighted in the sequence 9,8 , $7,4,5,6,3,2,1$. Hence, the key lights moved by horizontal rows, from lower to upper keys, across the response panel.

\section{RESULTS}

Figure 2 shows the data generated during the first four sessions. Each panel shows an entire session and which key was pecked on each trial. Panel 1, the first session,

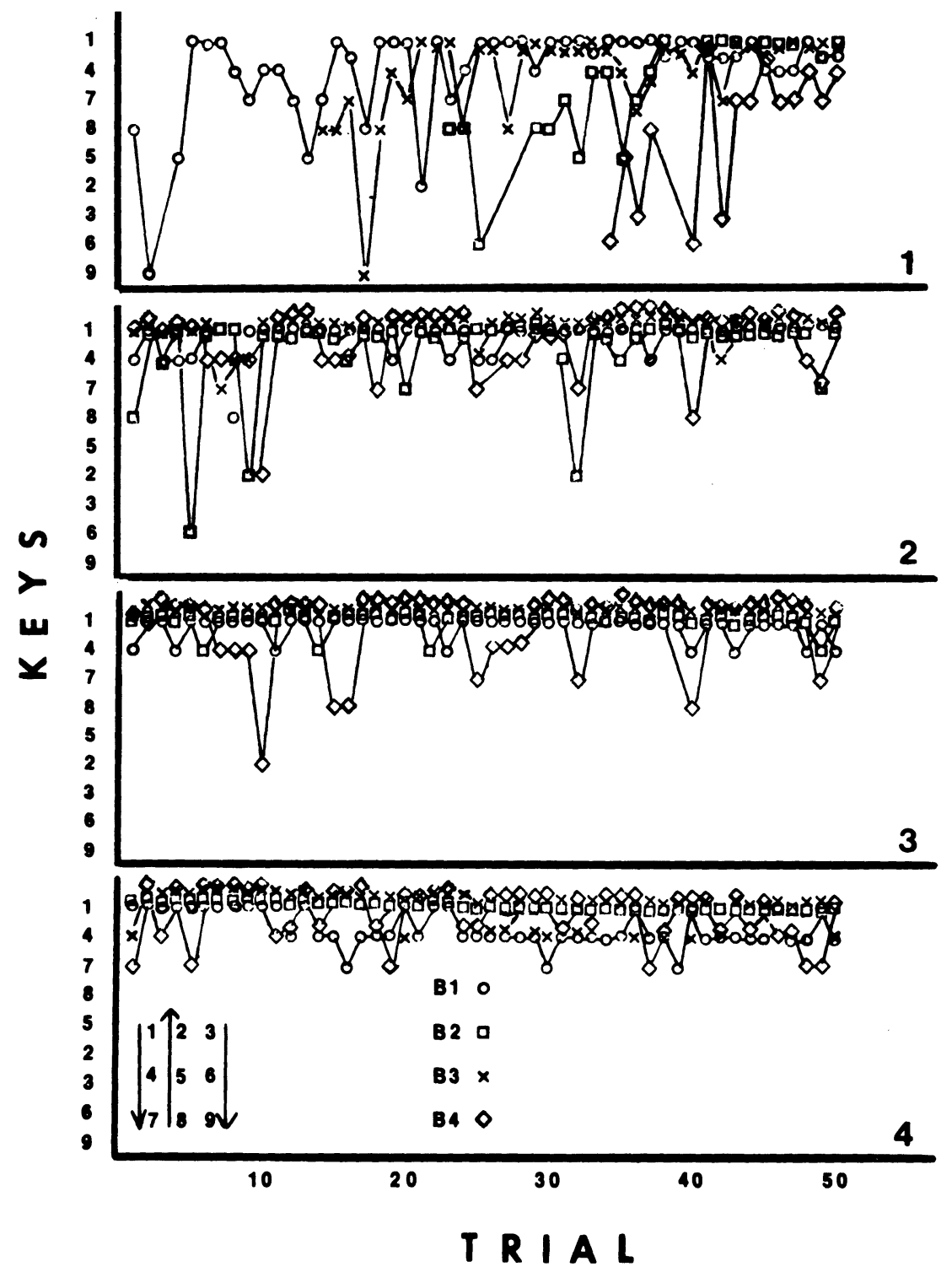

Figure 2. Response made during Sessions 1 (upper panel) through 4 (lower panel), inclusive. The abscissa represents all 50 trials of each session; the ordinate depicts the response keys that were pecked. The keys are shown in the order in which they were lighted. Thus, the first keys to light (CS1, CS2, etc.) are at the top of each ordinate. The lower left side of Panel 4 illustrates CS presentation order. 
reveals that the first keypeck from Birds B1, B2, B3, and B4 emerged during Trials $1,23,14$, and 34 , respectively $($ mean $=18)$. Three of the four birds-B1, B2, and B3emitted their first keypeck on the fourth key to light (Key 8), and Bird B4 pecked Key 6 first. By the end of the first session, each bird was predominantly pecking one of the first three keys to light. With the exception of one or two trials, each pigeon pecked a key during every trial after the first keypeck emerged. Figure 2 shows that each bird pecked a key during every trial of Sessions 2, 3, and 4. Furthermore, of the 726 cumulative keypecks emitted by the four birds during the first four sessions, $73 \%, 19 \%$, and $5 \%$ of the responses were to the first, second, and third key to light, respectively.

Figure 3 shows the data generated during the last three sessions of the study. The top panel, Session 5, indicates that each bird continued to peck predominantly one of the first two keys to light during each trial. During Sessions 6 and 7, the CS presentation order was changed. The middle and lower panels of Figure 3 show that each bird con- tinued to peck one of the first two keys to light. That is, during Sessions 6 and 7, each bird immediately shifted from pecking Keys 1 and 4, as they had during Sessions 1 through 5, and pecked Keys 9 and 8 instead.

\section{DISCUSSION}

The data suggest that when nine consecutive CS stimuli are provided, the first keypeck will be a response to one of the first, rather than to one of the last, CS stimuli to appear. After the first keypeck occurs, a response occurs reliably during each trial. Furthermore, the birds predominantly peck the first or second CS provided regardless of the key on which it appears.

If the keylight CS stimuli obtain their ability to produce a keypeck due to temporal contiguity with the US, we would have anticipated different results. We would have expected the last CS presented to have the strongest association with the US. Therefore, the first keypeck should have been to CS9. Via generalization mechanisms, this would be followed by a gradual shift of responses to the first keys lighted. Three of the four birds initially pecked the fourth key to light and then quickly shifted their pecks to the first keys to light. Thus, the informativeness of, rather than the temporal contiguity with, the US appears to exercise more control over behavior (Allaway, 1971; Egger \& Miller, 1962, 1963; Gamzu

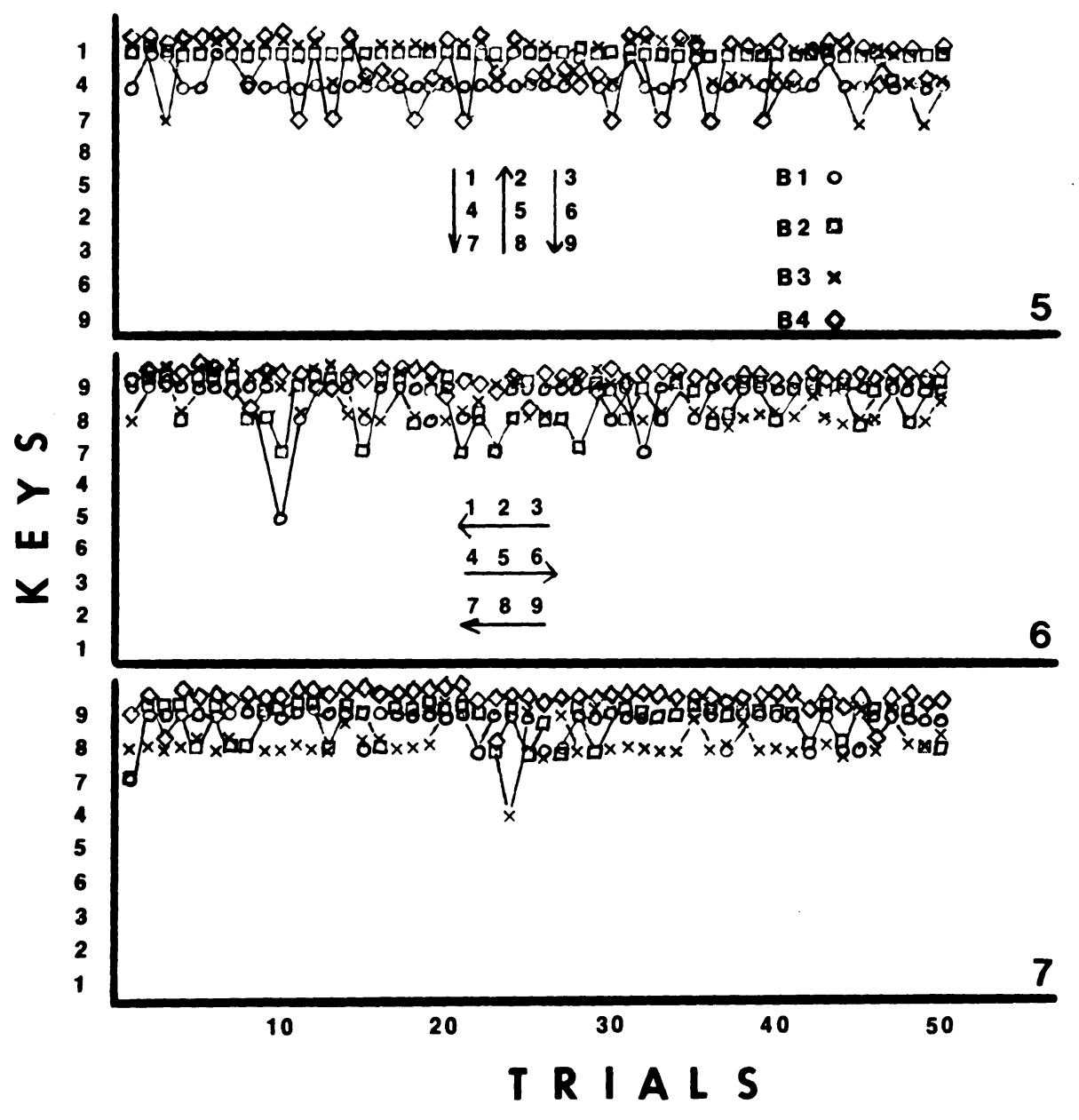

Figure 3. Responses made during Sessions 5 (upper panel) through 7 (lower panel), inclusive. The abscissa represents all 50 trials of each session; the ordinate depicts the response keys that were pecked. The keys are shown in the order in which they were lighted. 
\& Williams, 1971, 1973; Pisacreta, Redwood, \& Witt, 1983; Rescorla, 1972).

Additionally, since a key is lighted for only $2 \mathrm{sec}$, the birds would have to be vigilant during the ITIs in order to peck reliably CS1 or CS2 during the majority of the trials. Brown and Jenkins (1968) reported that two CS stimuli produced the autoshaped keypeck faster than one CS did. The present study shows that nine CS stimuli yield a keypeck in fewer trials than two CS stimuli. The fact that nine CS stimuli are more informative than one or two CS stimuli may account for the faster acquisition in the present study than in the other studies.

Increasing the number of CS stimuli also lengthens the CS interval. A longer CS interval provides more opportunity to form associations between stimuli, as well as more time to respond. However, Baldock (1974) reported that birds trained with a 4-sec CS interval required fewer trials before a keypeck was produced than did birds exposed to a 32 sec CS interval. Hence, we believe that it was the number of CS stimuli presented during the CS interval, rather than the overall CS length, that produced the results in the present study.

\section{REFERENCES}

Allaway, T. A. (1971). Attention, information, and autoshaping. Unpublished doctoral dissertation, University of Pennsylvania.

BALDock, M. D. (1974, April). Trial and intertrial interval durations in the acquisition of autoshaped key pecking. Paper presented at the meeting of the Eastern Psychological Association, Philadelphia. Brown, P. L., \& Jenkins, H. M. (1968). Auto-shaping of the pigeon's keypeck. Journal of the Experimental Analysis of Behavior, 11, 1-8.

EGGER, D., \& MiLlER, N. (1962). Secondary reinforcement in rats as a function of information value and reliability of the stimulus. Journal of Experimental Psychology, 64, 97-104.

EGgeR, M. D., \& MiLler, N. E. (1963). When is a reward reinforcing? An experimental study of the information hypothesis. Journal of Comparative and Physiological Psychology, 56, 132-137.

GamzU, E., \& Williams, D. R. (1971). Classical conditioning of a complex skeletal response. Science, 171, 923-925.

GamzU, E. R., \& Williams, D. R. (1973). Associative factors underlying the pigeon's keypecking in autoshaping procedures. Journal of the Experimental Analysis of Behavior, 19, 225-232.

Pavlov, I. P. (1927). Conditioned reflexes. London: Oxford University Press.

Pisacreta, R., Redwood, E., \& Witt, K. (1983). Autoshaping with several concurrently available conditioned stimuli. Bulletin of the Psychonomic Society, 21, 65-68.

ResCorla, R. A. (1972). Informational variables in Pavlovian conditioning. In G. H. Bower (Ed.), The psychology of learning and motivation (Vol. 6). New York: Academic Press.

(Manuscript received for publication October 5, 1984.) 